\title{
How I Treat Adult Acute Myeloid Leukemia
}

\author{
Tapan K. Saikia'
}

'Department of Medical Oncology, Prince Aly Khan Hospital, Mumbai, Maharashtra, India Medical ,Oncology Prince Aly Khan Hospital, Mumbai, Maharashtra, India

Ind J Med Paediatr Oncol 2021;42:182-189.

\section{Introduction}

In the mind of a reader, the first query would be, do I need to read another review article written by an Indian physician when I get to read everything on the multiple platforms on the internet? Such reaction is a valid one, given the avalanche of information and limited time available to read. Nevertheless, on request of the editorial board I accepted the challenge, and have included some relevant Indian publications.

Acute myeloid leukemia (AML) is a heterogeneous disorder and a very challenging pathology, though not fully unraveled yet. ${ }^{1-5}$ While nonrandom cytogenetic and molecular abnormalities have provided opportunity for a better classification, we still have a sizeable number of cases in whom the pathology is poorly understood, and they continue to receive old chemotherapy regimens and hematopoietic stem cell transplantation (HSCT) whenever possible. Additionally, incidence of Myelodysplastic syndrome (MDS) associated AML and therapy-related AML is not insignificant; a subset of patient pausing maximum challenge. ${ }^{6-8}$

Acute promyelocytic leukemia (APL) can now be treated very effectively with nonchemotherapy-based regimens and a small subset deriving added benefit from inclusion of chemotherapy drugs like daunorubicin, idarubicin, and antibody drug conjugate gemtuzumab ozogamycin (GO).9-12 I will not discuss about APL in this review, as it needs a dedicated article.

\section{Diagnosis}

As a referral center, I always get to see a patient after a reasonably accurate diagnosis is done elsewhere. Hence, I immediately request following investigations, mostly on a marrow sample (rarely on peripheral blood, provided blasts cells are more than $20 \%$, if the patient refuses to consent or only supportive care is the goal; - Table 1). As frequent dialogues are necessary to arrive at q rapid and confirmed diagnosis, I
Address for correspondence Tapan K. Saikia, MD, Medical Oncology, Prince Aly Khan Hospital, Nesbit Road, Mumbai 400010, Maharashtra, India (e-mail: tapan.saikia@gmail.com).

outsource sample to a laboratory where the hematopathologists are available for discussions to clarify doubts.

Morphology: As per the European LeukemiaNet (ELN) guideline and World Health Organization (WHO) classification, presence of $20 \%$ or more blasts after examining 200 leucocytes on a peripheral blood smear or 500 cells on marrow smear is necessary to proceed with further work up. ${ }^{1,13}$ However, in cases with $\mathrm{t}(15 ; 17), \mathrm{t}(8 ; 21)$, inv(16), or $\mathrm{t}(16 ; 16)$, even $10 \%$ or more blasts should be acceptable for confirming the diagnosis. Hence, awaiting these reports (takes $\sim 3-5$ days turnaround time) is worthwhile. Additionally, AML with monocytic or myelomonocytic differentiation, only monoblasts and promonocytes are to be counted to differentiate from chronic myelomonocytic leukemia (CMML).

Immunophenotyping: The full panel of cell surface and cytoplasmic markers (CD13, CD14, CD33, CD34, CD36, CD41, CD61, CD64, CD65, CD64, CD117, and Human Leucocyte Antigen DR [HLA-DR]) should be included and when necessary markers for mixed phenotypic acute leukemia panel [Mixed-phenotype acute leukemia (MPAL) Myelo-peroxidase (MPO), Cluster of differentiation (CD) CD3, CD10, CD11c, CD14, CD19, cCD22, CD64, and CD79a] should be asked for.

Cytogenetics and molecular cytogenetics: It is crucial to ask for conventional karyotyping to detect all known nonrandom, random, or novel cytogenetic abnormalities to understand prognosis, therapeutic decision-making, and new information. Polymerase chain reaction (PCR) technology has become a boon for availing information on recurring abnormalities. For patients who understand and generate adequate funds for optimal treatment, we are now integrating next-generation sequencing (NGS), as it is an extremely powerful technique offering deeper insight into the disease biology.

For unified classification of various hematological neoplasms, currently WHO classification is followed by nearly all, the latest one published in $2016 .{ }^{1}$
DOI https://doi.org/ 10.1055/s-0041-1732825 ISSN 0971-5851
(C) 2021. Indian Society of Medical and Paediatric Oncology.

This is an open access article published by Thieme under the terms of the Creative Commons Attribution-NonDerivative-NonCommercial-License, permitting copying and reproduction so long as the original work is given appropriate credit. Contents may not be used for commercial purposes, or adapted, remixed, transformed or built upon. (https://creativecommons.org/licenses/by-nc-nd/4.0/).

Thieme Medical and Scientific Publishers Private Ltd. A-12, Second Floor, Sector -2, NOIDA -201301, India 
Table 1 Tests performed for diagnosis and initial treatment

- Complete blood count (CBC) with full manual white cell count differential

- Bone marrow aspirate (trephine biopsy is optional-dry tap, research protocol)

- Immunophenotyping

- Cytogenetics: karyotyping

- Gene mutations and rearrangement: RT-PCR, NGS

- NPM1, CEBPA, RUNX1, FLT3, TP53, ASXL1, PML-RARA, CBFBMYH11, RUNX1-RUNXT1, BCR-ABL, any other as per ability of a specialized laboratory

- Demographics and medical history

- Family history

- Performance status

- Hepatitis B, C and HIV-1

- Blood chemistry: LFT, RFT, uric acid, LDH, electrolytes

- Coagulation profile

- Lumber puncture, especially in children or on clinical suspicion

- Chest X-ray, ECG, 2DECHO/MUGA

- Biobanking

- HLA-typing (often at a later date), CMV-PCR, for patients potential candidates for allogeneic transplants

Abbreviations: FLT3, fms-like tyrosine kinase 3; NPM1, Nucleophosmin 1; CEBPA, CCAAT/Enhancer binding, protein alpha; RUNX 1, Runt-related transcription factor 1; TP53, Tumor Protein 53; ASXL 1, additional sex comb-like 1; PML-RARA, promyelocytic leukemia/retinoic acid receptor alpha; CBFB-MYH11, Core Binding Factor Beta sub unit/Myosin Heavy Chain; BCR-ABL, Breakpoint Cluster Region-Abelson; 2D-ECHO, 2-dimensional echocardiography; MUGA, Multigated Acuqisition scan; HLA, human leucocyte antigen; ECG, electrocardiogram; LFT, liver function test; LDH, lactate dehydrogenase; NGS, next-generation sequencing; RFT, renal function test; RT-PCR, reverse transcription polymerase chain reaction.

In larger institute, it should be a regular practice to biobank (following ethical and scientific process) the cells for further study. It is truly a valuable bank, and we were greatly benefitted by one at Tata Memorial Hospital.

The relevant workup for starting treatment that includes blood biochemistry, coagulation profile, electrolytes, viral markers (sometimes there could be need for extensive workup), surveillance culture (a debatable issue, we do not practice), chest X-ray (computed tomography [CT] scan of chest, abdomen and others, or magnetic resonance imaging [MRI]-in selected cases, based on justified clinical judgement) is completed.

Genetic stratification is becoming increasingly important to understand disease biology, prognosis, possible of drug toxicity, genetic counselling, and planned treatment (-Table 2).

\section{Supportive Care}

The first issue I try to solve before admitting a patient of AML is that, all necessary supportive care, antimicrobials, blood components, central venous device (CVD) care, nutrition, etc., are in place. This remains a challenge in many places in India. With a good reason, I am not a great proponent of prophylactic oral antibiotics; however, we now routinely use antifungal throughout the treatment course. ${ }^{14-17}$ For febrile neutropenia, our institutional practice at present is monotherapy, a carbapenem, based on microbiology data. Addition of colistin happens in a significant number. We have not used an aminoglycoside for a long period. Third-line antibiotic is vancomycin or teicoplanin.
Table 2 Genetic Stratification

\begin{tabular}{|c|}
\hline Classification \\
\hline $\begin{array}{l}\text { Myeloid neoplasms with germ-line predisposition with- } \\
\text { out preexpressing disorder or organ dysfunction }\end{array}$ \\
\hline AML with germ-line CEBPA mutation \\
\hline Myeloid neoplasms with germ-line DDX41 mutation \\
\hline $\begin{array}{l}\text { Myeloid neoplasms with germ-line predisposition and } \\
\text { preexisting platelet disorders }\end{array}$ \\
\hline Myeloid neoplasms with germ-line RUNX1 mutation \\
\hline Myeloid neoplasms with germ-line ANKRD26 mutation \\
\hline Myeloid neoplasms with germ-line ETV6 mutation \\
\hline $\begin{array}{l}\text { Myeloid neoplasms with germ-line predisposition and } \\
\text { other organ dysfunction }\end{array}$ \\
\hline Myeloid neoplasms with germ-line GATA2 mutation \\
\hline $\begin{array}{l}\text { Myeloid neoplasms associated with bone marrow failure } \\
\text { syndrome }\end{array}$ \\
\hline $\begin{array}{l}\text { Juvenile myelomonocytic leukemia associated neurofi- } \\
\text { bromatosis, Nooman's syndrome like disorders }\end{array}$ \\
\hline Myeloid neoplasm associated with Nooman's syndrome \\
\hline Myeloid neoplasms associated with Down's syndrome \\
\hline Guide for molecular genetic diagnostics \\
\hline $\begin{array}{l}\text { Myelodysplastic predisposition/acute leukemia predispo- } \\
\text { sition syndromes }\end{array}$ \\
\hline $\begin{array}{l}\text { CEBPA, DDX41, RUNX1, ANKRD26, ETV6, GATA2, SRP72, } \\
\text { 14q32.2 genomic duplication (ATG2B/GSKIP) }\end{array}$ \\
\hline Cancer disposition syndromes \\
\hline Li Fraumeni syndrome (TP53) \\
\hline Germ-line BRCA/BRCA2 mutations \\
\hline Bone marrow failure syndromes \\
\hline Dyskeratosis congenita (TERC, TERT) \\
\hline
\end{tabular}

Therapeutic antifungal is an echinocandin, amphotericin reserved for later use. For blood components, we followed the Association of American Blood Bank guidelines. Antivirals are not a part of routine therapy during induction; those are used only for allogeneic transplant cases. For CVD care, we have a dedicated nursing team. We do not use growth factor support-cerebrospinal fluid (G-CSF) in the induction phase but have been practicing during postremission therapy with high-dose cytarabine. ${ }^{18}$

\section{Acute Myeloid Leukemia Directed Therapy}

I try to take no half measures while managing a freshly diagnosed young patient with AML. Over multiple sessions, patients and families are explained and counselled about every aspect of the disease and management such as chemotherapy, biologicals, blood components, antimicrobials, need for stem cell transplants, donor selection, cost, prognosis and outcome, and duration of treatment. As it happens across India and other middle- and low-income countries (MLIC), only a small number can accept current standard of care. I follow ELN guidelines and most recent published upd ates. ${ }^{2,3,19-25}$ 


\section{Induction of Remission}

Since the middle of 1980s, we have continued to use the 3 +7 regimen of daunorubicin and cytarabine. We explored daunorubicin doses of 45 and $60 \mathrm{mg}$ and $90 \mathrm{mg} / \mathrm{m}^{2}$ daily for 3 days, finally settling down on $60 \mathrm{mg} / \mathrm{m}^{2}$ dose. ${ }^{13,26-29}$ We used idarubicin very sparingly, given its high cost and nonsuperiority. ${ }^{30}$ Cytarabine dose has always been $100 \mathrm{mg} / \mathrm{m}^{2} /$ day continuous intravenous infusion for 7 days, although we are aware that $200 \mathrm{mg}$ also could be used. We have not explored intermediate or high-dose cytarabine, as these are known to cause higher complications..$^{28}$ If the first cycle fails to achieve a morphological remission, we use high-dose cytarabine at a 1.5 to $3 \mathrm{~g} / \mathrm{m}^{2}$ in every 12 hours for six doses on 3 consecutive days or on days 1, 3, and 5.,13,31 Addition of targeted agents, like FLT3 inhibitors, has not improved remission rate significantly but impacted event-free and overall survival (EFS and OS). ${ }^{32,33}$ However, promises are plenty for use of novel agents in induction and postremission phases. ${ }^{34}$

Institution of chemotherapy is usually considered an urgency, if not an emergency, except in cases of APL; however, a recent report, the Beat AML study, has shown that a wait period of 7 days is safe, the time needed for turnaround of genetic information. ${ }^{35}$

\section{Postremission Therapy}

I have tried to address the three approaches of postremission therapy as follows: (1) high-dose cytarabine-based chemotherapy, (2) allogeneic HSCTs and (3) autologous HSCT through case vignettes from our own experience. I have tried to include the issues of donor selection, minimal residual disease (MRD), and novel drugs.

Case 1: A 32-year-old female, was diagnosed to have AML with normal cytogenetics with NPM-1 mutation and FLT3 negativity in 2010. A complete remission was achieved with one cycle of $3+7$ of daunorubicin $60 \mathrm{mg} / \mathrm{m}^{2} /$ day $\times$ 3 days and cytarabine $100 \mathrm{mg} / \mathrm{m}^{2} /$ day $\times 7$ days. Subsequently four cycles of high-dose cytarabine at 4 - to 5 -week intervals were administered. She remains disease free till date with no long-term effects of therapy.

High-dose cytarabine is now administered in a dose varying from $1 \mathrm{G} / \mathrm{m}^{2} / 12$ hours $\times$ six doses on consecutive or on alternate days to $3 \mathrm{G} / \mathrm{m}^{2} / 12$ hours $\times$ six doses at 4 -week intervals with no significant difference in outcome. ${ }^{28,29,31}$ We offer lower dose to patients over 50 years of age. All standard- and some intermediate-risk patients are eligible for this postremission therapy. Addition of anthracycline does not improve outcomes.

Case 2: A 39-year-old male, was diagnosed to have a poor-risk cytogenetics AML with trisomy 8 and mixed-lineage leukemia (MLL) translocations, when he presented with repeated febrile episodes and increasing fatigue in recent months. He received a $3+7$ regimen of daunorubicin $60 \mathrm{mg} / \mathrm{m}^{2} /$ day $\times 3$ and cytarabine $100 \mathrm{mg} / \mathrm{m}^{2} /$ day continuous intravenous for 7 days. He had a stormy postinduction phase that needed multiple antimicrobials. Although there was a morphologic remission, MRD was positive. Then he received one cycle of high-dose cytarabine, $2 \mathrm{~g} / \mathrm{m}^{2} / 12$ hours $\times$ six doses on days 1,3 , and 5 . Within 3 months of initial therapy, he received an allogeneic peripheral blood stem cell transplantation (PBSCT) from an HLA- and blood group-matched female sibling donor, following a melphalan and fludarabine conditioning chemotherapy. Posttransplant course was largely uneventful barring a brief neutropenic fever and minimal blood component requirement. There was no cytomegalovirus (CMV) reactivation or graft versus host disease (GVHD). There was no planned Donor Leucocyte Infusion (DLI) for patients who do not develop GVHD. Unfortunately, his disease relapsed 5 months after transplant. An attempt to induce a remission with the fludarabine + high-dose cytarabine + Granulocyte-Colony Stimulating Factor (FLAG) chemotherapy proved to be fatal.

This case raises the issues of outcome in poor-risk AML following current standard of care at 5-years. ${ }^{13,28,35}$ If a transplant is not feasible, the outcome is less than 15 and 35 to $45 \%$ following a transplant. ${ }^{28}$ Should he have received a myeloablative conditioning regimen, Total Body irradiation (TBI) Fluorescent in-situ hybridization (FISH)-based or chemotherapy based? The issue remains unresolved with differing results from different trials. ${ }^{32-40}$

Logistically, MRD or measurable residual disease assessment following every phase of treatment should have an extremely powerful prognostic determinant and a base for clinical trials. ${ }^{41-44}$ In B-precursor cell, the role of acute lymphoblastic leukemia (ALL) has been established and being actively used across the globe. AML being a biologically more heterogenous disorder and abnormalities detected with various techniques (cytogenetics, FISH, PCR, and NGS), not to mention the numerical burden of mutations makes MRD assessment more challenging. Currently, multiflow cytometry using minimum eight-panel antibodies is frequently used. ${ }^{45}$ However, assessing individual abnormalities by molecular techniques have pertinent value. Nevertheless, it is a dynamic field and cannot be used in routine practice.

Case 3: A 27-year-old female, was diagnosed to have poor-risk AML (>10 abnormalities), following investigations for severe anemia. A $3+7$ induction chemotherapy with daunorubicin and cytarabine could produce only a partial remission and a high-dose cytarabine therapy of $2 \mathrm{G} / \mathrm{m}^{2} \times$ six doses produced a morphological remission but with MRD positivity. She did not have a sibling donor; upon search, a 9/10-matched donor was found. While waiting for the transplant, she received another cycle of chemotherapy with single-agent cladribine and achieved an MRD negative status. She underwent matched-unrelated donors (MUD) transplant with melphalan + fludarabine conditioning and short methotrexate + cyclosporine for GVHD prophylaxis; 5-month posttransplant remains in graft and relapse-free survival (GRFS). It is still too early to realize whether the treatment has been curative!

This case emphasizes the importance of an allogeneic transplant from a suitable donor. MUD transplants appear to be safe and outcomes as good as sibling donor transplants if HLA match is $10 / 10$ or $9 / 10$ (50-52). However, the procedure is expensive and the challenge of finding a donor on time remains. Whether a haploidentical transplant could be more practical in an Indian setting, is a matter of discussion. 
Donor selection for allogeneic transplant is important. ${ }^{28,46-48}$ While HLA-matched sibling donor is a first choice, lack of these donors for majority of eligible patients, alternative donors, namely, MUD, mismatched unrelated donors, and haploidentical donors are chosen. Outcome of such alternative donor transplants is improving. For MUD, 8/8 match is considered optimal; mismatch of one or more allele, the survival outcomes are inferior by $10 \%$ for each allele. Currently, most centers look for 10/10- or 9/10-matched donors.

Case 4: A 44-year-old female, was diagnosed to have an FLT3-internal tandem duplication (ITD)-positive AML and failed to achieve morphological remission with a $3+$ 7 idarubicin and cytarabine + midostaurin induction therapy. Reinduction with high-dose cytarabine caused a prolonged neutropenic period lasting for more than 6 weeks. The marrow was hypocellular with no excess blasts. She was advised an allogeneic HSCT and her 42-year-old brother was found to be HLA identical. As she needed to raise funds for the procedure, she was advised to continue treatment with 5-azacytidine and sorafenib. She could receive 5-azacytidine but due to persistent neutropenia, sorafenib was omitted. She underwent transplant with busulfan + fludarabine conditioning and posttransplant cyclophosphamide (PTCY) for GVHD prophylaxis, a year after initial therapy. Posttransplant period was complicated by a short bacterial infection and need for moderate blood components. However, 4 weeks after posttransplant, she developed grade-IV thrombocytopenia and deranged liver function test (LFT). CMV copies were elevated to 1,350 copies/mL of blood. After being diagnosed as CMV hepatitis, she received a 3-week course of ganciclovir along with platelet support. CMV level returned to normal and LFT improved. Around the same time, skin rash was diagnosed as acute GVHD grade 1 and received methylprednisolone, followed by oral prednisolone. Her CMV and limited GVHD recurred and possibly BK virus-associated cystitis developed few months post-transplant and prednisolone, monitored by a local physician who is new to such care, we remain in constant touch.

Abnormalities in the FLT3 gene, either in the form of ITD in 15 to $25 \%$, more common in younger population or mutations in the tyrosine kinase domain (D835TKD) in 5 to $10 \%$ of population. In last two decades, several targeted drugs and FLT3 inhibitors have been developed and clinical trials done. ${ }^{49-53}$ Currently, approved ones are midostaurin, quizartinib, crenolanib, and gilteritinib. Midostaurin used at a 50-mg twice daily dose included in the induction regimen and postremission phase and maintenance for a year, the phase- 3 randomized RATIFY trial showed significantly improved EFS in younger patients. ${ }^{49,50}$ Clearly, more potent inhibitors are needed. Sorafenib, a multikinase inhibitor, showed its potential, but till date, no phase- 3 has been published. ${ }^{54}$ While it is somewhat easier to administer for chemotherapy-alone patients, these agents cannot be administered as smoothly following allogeneic transplants due to various complications like infections, GVHD, and hamper frequently.

At this point, I take the opportunity of mentioning novel drugs that have been approved or undergoing clinical trials
(-Table 3). It is beyond the scope of this article to mention details of each drug, clinical trials, and outcome. I request readers to refer to two excellent recent publications. ${ }^{51,53}$ Advent of these novel agents has brought about a revolution in treating elderly patients and some of relapsed cases. As time progresses, these will move onto treatment of newly diagnosed young patients.

Case 5: R.P., a 22-year-old male, was diagnosed with good risk $t(8,20)$ AML with normal white cell count. A morphologic remission was achieved with a $3+7$ regimen. Following a high-dose cytarabine postremission therapy, he was explained regarding further chemotherapy or a high-dose chemotherapy [Busulphan and Cyclophosphamide (BUCY) regimen] with autologous blood stem cell transplant (ASCT). He accepted ASCT and now 10 years later lives a normal life, married and father of a child. Long-term follow-up data from Electronic Bone Marrow Transplant (EBMT) Registry show that ASCT could be superior to intensive chemotherapy in good risk and intermediate risk cases. ${ }^{36}$ In my opinion, ASCT remains a reasonable option if an experienced center has an extremely low transplant-related mortality rate.

Case 6: A 32-year-old female, presented with fatigue of two weeks duration. A complete blood count (CBC) revealed white blood cell $(\mathrm{WBC})$ of $76 \times 10^{9} / \mathrm{L}$ with $70 \%$ circulating blasts; hemoglobin, $6 \mathrm{~g} / \mathrm{dL}$; and platelets, $230 \times$ $10^{9} / \mathrm{L}$. Immunophenotype confirmed AML with monocytic

Table 3 Novel drugs for treatment of acute myeloid leukemia (AML)

\begin{tabular}{|c|c|c|}
\hline Drugs & $\begin{array}{l}\text { Type of } \\
\text { treatment }\end{array}$ & Studies \\
\hline \multicolumn{3}{|l|}{ FLT3 inhibitors } \\
\hline $\begin{array}{l}\text { Midostaurin } \\
\text { (oral) }\end{array}$ & Phase III & $\begin{array}{l}\text { With chemotherapy (pla- } \\
\text { cebo controlled) RATIFY }\end{array}$ \\
\hline \multicolumn{3}{|l|}{ Quizartinib } \\
\hline Gilteritinib (oral) & Phase III & $\begin{array}{l}\text { Vs. salvage chemotherapy } \\
\text { ADMIRAL }\end{array}$ \\
\hline \multicolumn{3}{|l|}{ IDH $1 / 2$ inhibitors } \\
\hline Enasidenib (oral) & Phase I/II & \\
\hline Ivosidenib (oral) & Phase I/II & \\
\hline \multicolumn{3}{|l|}{ BCL-2 inhibitor } \\
\hline $\begin{array}{l}\text { Venetoclax } \\
\text { (oral) }\end{array}$ & $\begin{array}{l}\text { Ib/II for adults } \\
\geq 75 \text { years old }\end{array}$ & Study M14-387 \\
\hline \multicolumn{3}{|l|}{$\begin{array}{l}\text { Hedgehog } \\
\text { (Hh) pathway } \\
\text { inhibitors }\end{array}$} \\
\hline Glasdesib (oral) & Phase II & Randomized BRIGHT \\
\hline \multicolumn{3}{|l|}{ Chemotherapy } \\
\hline CPX-351 (oral) & Phase III & Vs. $3+7$ regimen \\
\hline $\begin{array}{l}\text { Gemtuzumab } \\
\text { ozogamicin } \\
\text { (GO) }\end{array}$ & Phase III & $\begin{array}{l}\text { Vs. best supportive care } \\
\text { EORTC-GIMEMA AML-19 } \\
\text { Vs. } 3+7 \text { regimen } \\
\text { ALFA-0701 }\end{array}$ \\
\hline
\end{tabular}


differentiation. A marrow aspirate was dry, apparently due to a packed marrow; a trephine was possible. Peripheral blood could be studied for karyotyping, a normal cytogenetics. NGS molecular diagnostics revealed NPM-1 mutation, IDH mutation and DNMT3 mutation; FLT3 mutations were negative. As per current prognostic criteria, she falls in the favorable group with $85 \%$ possibility of a cure with or without an HCT. ${ }^{5,55}$ She received induction therapy with $3+7$ regimen of daunorubicin $60 \mathrm{mg} / \mathrm{m}^{2} /$ day $\times 3$ and cytarabine $100 \mathrm{mg} / \mathrm{m}^{2} / \mathrm{d}$ civ $\times 7$. Following required supportive care, her blood counts normalized on day 20. A marrow aspirate was easy this time; it showed morphological complete remission and MRD negative by eight-panel flow (sensitivity 3 log reduction). We are discussing with her regarding further care with three more cycles of postremission therapy or offer an allogeneic HCT if her only sister is HLA identical.

\section{Treating Elderly Acute Myeloid Leukemia Patients}

AML being disease of elderly, who are unable to tolerate aggressive therapy due to physiological decline in health and associated comorbidities, has been receiving only symptomatic care. However, with the availability of epigenetic therapy like 5-azacitidine and decitabine, currently a significant number of elderly patients receive these agents and some derive long-term benefit. ${ }^{56}$ Intense research in this field has led to development of several novel drugs targeting pathways responsible for leukemogenesis. These have helped to treat a larger number of elderly patients.

Current trend is to offer a combination of 5-azacitidine and venetoclax for majority of elderly patients, if a molecular target has not been detected. ${ }^{57}$ This combination calls for excellent supportive care as venetoclax produces deep cytopenia. The dose of this agent needs to be ramped up within 3 to 4 days, starting at $100 \mathrm{mg}$ on day 1, $200 \mathrm{mg}$ on day 2, $300 \mathrm{mg}$ on day 3 , and $400 \mathrm{mg}$ from day 4 onward; there is no benefit in reducing the dose, rather a period should be allowed for marrow recovery.

Good-risk patients with good performance status, which comprise only approximately $10 \%$ of all elderly AML population, should be candidates for aggressive therapy as offered to the young patients. Of greater significance, development of novel drugs targeting various pathways responsible for leukemogenesis, such as FLT-3, IDH1/2, BCL-2, and immune checkpoints, have opened up the field for treatment of elderly patients; these agents are better tolerated; hence, outpatient care is feasible. $^{51,53,58-63}$

\section{Maintenance Therapy}

Studies have failed to show benefit of maintenance therapy in the form of chemotherapy, hypomethylating agents or biologicals, with or without a transplantation. ${ }^{64-66}$ However, investigators believe that research needs to be pursued in this area. ${ }^{67}$ Till date, maintenance using midostaurin, the FLT-3 inhibitor has shown survival benefit in a subset in the RATIFY trial. ${ }^{49,50}$ Similarly, addition of dasatinib to chemotherapy for CBF AML in CALGB 10801 study has shown encouraging 3-year DFS and OS. ${ }^{68}$ Of course, patients who have responded to epigenetic therapy or novel oral chemotherapy drug, continue to receive treatment for a long period, a few for indefinite time.

\section{The Indian Scenario}

While managing a difficult disease that involves intensive therapy, team work and availability of resources in a low- and middle-income country (LMIC), the perineal issue of offering the best available therapy comes up, AML being one of the most difficult illnesses. As a result, there is dearth of publications, although many centers across the country can now offer standard of care. Nonetheless, the stark reality is that only small fraction of patients receive such therapy. While searching the PubMed for AML in India, there were 500+ articles, most on diagnosis and case reports.

Published reports discuss challenges of treating AML patients; however, the outcomes appear to be comparable with the international studies. ${ }^{69-73}$ A 2-year prospective study done at Christian Medical College, Vellore, in 380 newly diagnosed cases (excluding APL) revealed that median age was younger (40 years) and compared with the western world; only $29 \%$ of patients could receive standard of care. ${ }^{69}$ Induction mortality was high $(24.7 \%)$, occurred due to MDR gram-negative bacilli (44.5\%) and fungal infections (44.5\%). Median survival varied according to the age. The same group published encouraging results in the area of allogeneic stem cell transplantation. ${ }^{70} \mathrm{~A}$ prospective multicentric study looked at invasive fungal infections following chemotherapy for acute myeloid leukemia. ${ }^{71}$ A couple of studies from North India (All India Institute of Medical Sciences [AIIMS]) and South India ([WIA] Adyar Cancer Institute) revealed issues in a real-world scenario. ${ }^{72,73}$

Our data on selected patients $(n=166)$ using standard 3 +7 regimen, followed by two cycles of high-dose cytarabine $\left(15-18 \mathrm{G} / \mathrm{m}^{2}\right)$ and four more cycles of lower dose outpatient daunorubicin and cytarabine showed (CR) Complete Response in $70 \%$, early mortality in $16 \%$, and 3 -year relapse-free survival and EFS in 34 and $22 \%$, respectively. ${ }^{74}$

Some physicians have incorporated metronomic chemotherapy in the supportive care and have shown improved EFS and long-term survival in a small fraction of patients. ${ }^{75,76}$ These are phase-II trials in a selective cohort, not intent to treat; therefore, a meaningful scientific conclusion is hazardous. However, if we look beyond pure science, should we not offer such treatment to as many as possible for the ones who cannot afford intensive therapy? To be honest, even the best academic centers in the country do not fail to mention an oral agent like mercaptopurine (6-MP) along with supportive care in the discharge card. Hence, I will not be the jury here; I appreciate efforts of colleagues who are involved in acute leukemia care in very trying environments.

\section{Resistance, Relapse, and Management}

Treatment related mortality (TRM) is consistently coming down due to improving supportive care. ${ }^{28}$ As a result, it is primary resistance, the incidence varying 10 to $40 \%$ depending on risk factors. ${ }^{28}$ The long-term outcome in primary resistance cases is dismal, although some can be salvaged with an allogeneic SCT. ${ }^{77-79}$ Prognosis depends on time of relapse; 
those who relapse with first 1 year have poor prognosis, as opposed to late relapses. Attempts to achieve a second remission with another chemotherapy regimen meets with varying success, usually less than $50 \%$ and remission duration is short. Some studies have shown that a favorable outcome could be possible if an allogeneic SCT could be done in early relapse cases. Clearly, newer approaches are needed for relapsed AML. Clinical trials using novel drugs, Chimeric Antigen Receptor (CAR) T-cell therapies ${ }^{80}$ are to be explored whenever possible. I spend a sufficient time with patients and families explaining the situations.

More exciting is the development of numerous novel agents that have therapeutic targets. These agents have made it possible to treat relapsed cases, as well as elderly patients as a first-line therapy. - Table $\mathbf{3}$ shows a summary of these agents.

\section{Conclusion}

Our understanding of biology of AML has improved significantly. It remains a work in progress and much more remains to be understood, especially about the leukemia stem cells. Probably there lies the Achilles heel(s), emphasizing the need for development of more effective compounds. Current knowledge has helped to cure most of APL cases, given its unique biology of single molecular abnormality in more than $90 \%$ cases; exemplified by the Chronic Myeloid Leukemia (CML) model as well. However, cooperation of multiple mutations, some working as drivers of pathogenesis, makes treatment of all other types of AML hugely challenging. Hence, allogeneic transplants as a strategy to reduce relapse, continue to play an integral part of management for relapsed standard-, intermediate-, and poor-risk cases. Older AML patients who are not candidates for aggressive chemotherapy and/or allogeneic transplants, can now look for friendlier treatment approaches with tolerable therapy. Nevertheless, a cure still remains elusive for most of these people. A sober reminder, amidst all this excitement, survival improvement in younger patients remains modest; perhaps integration of novel biological molecules to chemotherapy agents will make an impact. We remain hopeful as the pace of progress in health science is painfully slow but the journey never stops.

\section{Conflict of Interest}

None declared.

\section{References}

1 Arber DA, Orazi A, Hasserjian R, et al. The 2016 revision to the World Health Organization classification of myeloid neoplasms and acute leukemia. Blood 2016;127(20):2391-2405

2 Döhner H, Weisdorf DJ, Bloomfield CD. Acute myeloid leukemia. N Engl J Med 2015;373(12):1136-1152

3 Ley TJ, Miller C, Ding L, et al. Cancer Genome Atlas Research Network. Genomic and epigenomic landscapes of adult de novo acute myeloid leukemia. NEnglJ Med 2013;368(22):2059-2074

4 Welch JS, Ley TJ, Link DC, et al. The origin and evolution of mutations in acute myeloid leukemia. Cell 2012;150(2):264-278
5 Patel JP, Gönen M, Figueroa ME, et al. Prognostic relevance of integrated genetic profiling in acute myeloid leukemia. N Engl J Med 2012;366(12):1079-1089

6 Jan M, Snyder TM, Corces-Zimmerman MR, et al. Clonal evolution of preleukemic hematopoietic stem cells precedes human acute myeloid leukemia. Sci Transl Med 2012;4(149):149ra118

7 Krönke J, Bullinger L, Teleanu V, et al. Clonal evolution in relapsed NPM1-mutated acute myeloid leukemia. Blood 2013;122(1):100-108

8 Jaiswal S, Fontanillas P, Flannick J, et al. Age-related clonal hematopoiesis associated with adverse outcomes. N Engl J Med 2014;371(26):2488-2498

9 Sanz MA, Grimwade D, Tallman MS, et al. Management of acute promyelocytic leukemia: recommendations from an expert panel on behalf of the European LeukemiaNet. Blood 2009;113(9):1875-1891

10 Osman AEG, Anderson J, Churpek JE, et al. Treatment of acute promyelocytic leukemia in adults. J Oncol Pract 2018;14(11):649-657

11 Lo-Coco F, Avvisati G, Vignetti M, et al. Gruppo Italiano Malattie Ematologiche dell'Adulto; German-Austrian Acute Myeloid Leukemia Study Group; Study Alliance Leukemia. Retinoic acid and arsenic trioxide for acute promyelocytic leukemia. N Engl J Med 2013;369(2):111-121

12 Mathews V, Chendamarai E, George B, Viswabandya A, Srivastava A. Treatment of acute promyelocytic leukemia with single-agent arsenic trioxide. Mediterr J Hematol Infect Dis 2011;3(1):e2011056

13 Döhner H, Estey E, Grimwade D, et al. Diagnosis and management of AML in adults: 2017 ELN recommendations from an international expert panel. Blood 2017;129(4):424-447

14 Klastersky J, de Naurois J, Rolston K, et al. ESMO Guidelines Committee. management of febrile neutropenia: ESMO Clinical Practice Guidelines. Ann Oncol 2016;27(suppl 5) :v111-v118

15 Gafter-Gvili A, Fraser A, Paul M, Leibovici L. Meta-analysis: antibiotic prophylaxis reduces mortality in neutropenic patients. Ann Intern Med 2005;142(12, pt 1):979-995

16 Furno P, Bucaneve G, Del Favero A. Monotherapy or aminoglycoside-containing combinations for empirical antibiotic treatment of febrile neutropenic patients: a meta-analysis. Lancet Infect Dis 2002;2(4):231-242

17 Cornely OA, Maertens J, Winston DJ, et al. Posaconazole vs. fluconazole or itraconazole prophylaxis in patients with neutropenia. N Engl J Med 2007;356(4):348-359

18 Mitchell S, Li X, Woods M, et al. Comparative effectiveness of granulocyte colony-stimulating factors to prevent febrile neutropenia and related complications in cancer patients in clinical practice: a systematic review. J Oncol Pharm Pract 2016;22(5):702-716

19 Mayer RJ, Davis RB, Schiffer CA, et al. Cancer and Leukemia Group B. Intensive postremission chemotherapy in adults with acute myeloid leukemia. N Engl J Med 1994;331(14):896-903

20 Sekeres MA, Guyatt G, Abel G, et al. American Society of Hematology 2020 guidelines for treating newly diagnosed acute myeloid leukemia in older adults. Blood Adv 2020;4(15):3528-3549

21 Walter RB, Othus M, Borthakur G, et al. Prediction of early death after induction therapy for newly diagnosed acute myeloid leukemia with pretreatment risk scores: a novel paradigm for treatment assignment. J Clin Oncol 2011;29(33):4417-4423

22 Medeiros BC, Satram-Hoang S, Hurst D, Hoang KQ Momin F, Reyes C. Big data analysis of treatment patterns and outcomes among elderly acute myeloid leukemia patients in the United States. Ann Hematol 2015;94(7):1127-1138 
23 Juliusson G, Antunovic P, Derolf A, et al. Age and acute myeloid leukemia: real world data on decision to treat and outcomes from the Swedish Acute Leukemia Registry. Blood 2009;113(18):4179-4187

24 Juliusson G, Abrahamsson J, Lazarevic V, et al. Swedish AML Group and the Swedish Childhood Leukemia Group. Prevalence and characteristics of survivors from acute myeloid leukemia in Sweden. Leukemia 2017;31(3):728-731

25 Dombret H, Seymour JF, Butrym A, et al. International phase 3 study of azacitidine vs conventional care regimens in older patients with newly diagnosed AML with $>30 \%$ blasts Blood 2015;126(3):291-299

26 Othus M, Kantarjian H, Petersdorf S, et al. Declining rates of treatment-related mortality in patients with newly diagnosed AML given 'intense' induction regimens: a report from SWOG and MD Anderson. Leukemia 2014;28(2):289-292

27 Sorror $M$, Storer $B$, Elsawy $M$, et al. Intensive versus non-intensive induction therapy for patients (pts) with newly diagnosed acute myeloid leukemia (AML) using two different novel prognostic models. Blood 2016;128:216

28 Estey EH. Acute myeloid leukemia: 2019 update on risk-stratification and management. Am J Hematol 2018;93(10):1267-1291

29 Burnett AK, Russell NH, Hills RK, et al. Optimization of chemotherapy for younger patients with acute myeloid leukemia: results of the medical research council AML15 trial. J Clin Oncol 2013;31(27):3360-3368

30 Lee J-H, Kim H, Joo Y-D, et al. Cooperative Study Group A for Hematology. Prospective randomized comparison of idarubicin and high-dose daunorubicin in induction chemotherapy foe newly diagnosed acute myeloid leukemia. J Clin Oncol 2017;35(24):2754-2763

31 Löwenberg B. Sense and nonsense of high-dose cytarabine for acute myeloid leukemia. Blood 2013;121(1):26-28

32 Østgård LSG, Lund JL, Nørgaard JM, et al. Impact of allogeneic stem cell transplantation in first complete remission in acute myeloid leukemia: a national population-based cohort study. Biol Blood Marrow Transplant 2018;24(2):314-323

33 Elsawy M, Sorror ML. Up-to-date tools for risk assessment before allogeneic hematopoietic cell transplantation. Bone Marrow Transplant 2016;51(10):1283-1300

34 Appelbaum FR. Impact of allogeneic hematopoietic cell transplantation on the outcome of older patients with acute myeloid leukemia. Best Pract Res Clin Haematol 2017;30(4):320-326

35 Gooley TA, Chien JW, Pergam SA, et al. Reduced mortality after allogeneic hematopoietic-cell transplantation. $\mathrm{N}$ Engl J Med 2010;363(22):2091-2101

36 Cornelissen JJ, Blaise D. Hematopoietic stem cell transplantation for patients with AML in first complete remission. Blood 2016;127(1):62-70

37 Kröger N, Iacobelli S, Franke GN, et al. Dose-reduced versus standard conditioning followed by allogeneic stem-cell transplantation for patients with myelodysplastic syndrome: a prospective randomized phase III study of the EBMT (RICMAC trial. J Clin Oncol 2017;35(19):2157-2164

38 Deeg HJ, Stevens EA, Salit RB, et al. Transplant conditioning with Treosulfan/Fludarabine with or without Total body irradiation: a randomized phase II trial in patients with myelodysplastic syndrome and acute myeloid leukemia. Biol Blood Marrow Transplant 2018;24(5):956-963

39 Scott BL, Pasquini MC, Logan BR, et al. Myeloablative versus reduced-intensity hematopoietic cell transplantation for acute myeloid leukemia and myelodysplastic syndromes. J Clin Oncol 2017;35(11):1154-1161

40 Fasslrinner F, Schetelig J, Burchert A, et al. Long-term efficacy of reduced-intensity versus myeloablative conditioning before allogeneic haemopoietic cell transplantation in patients with acute myeloid leukaemia in first complete remission: retrospective follow-up of an open-label, randomised phase 3 trial. Lancet Haematol 2018;5(4):e161-e169

41 Ivey A, Hills RK, Simpson MA, et al. UK National Cancer Research Institute AML Working Group. Assessment of minimal residual disease in standard-risk AML. N Engl J Med 2016;374(5):422-433

42 Jongen-Lavrencic M, Grob T, Hanekamp D, et al. Molecular minimal residual disease in acute myeloid leukemia. $\mathrm{N}$ Engl J Med 2018;378(13):1189-1199

43 Salk JJ, Schmitt MW, Loeb LA. Enhancing the accuracy of next-generation sequencing for detecting rare and subclonal mutations. Nat Rev Genet 2018;19(5):269-285

44 Patkar N, Kakirde C, Bhanshe P, et al. Utility of immunophenotypic measurable residual disease in adult acute myeloid leukemia- Real-World-Context. Front Oncol 2019;9:450

45 Schuurhuis GJ, Heuser M, Freeman $S$, et al. Minimal/measurable residual disease in AML: a consensus document from the European LeukemiaNet MRD Working Party. Blood 2018;131(12):1275-1291

46 Riezzo I, Pascale N, La Russa R, Liso A, Salerno M, Turillazzi E. Donor selection for allogeneic hematopoietic stem cell transplantation: clinical and ethical considerations. Stem Cells Int 2017;2017:5250790

47 Shouval R, Fein JA, Labopin M, et al. Outcomes of allogeneic haematopoietic stem cell transplantation from HLA-matched and alternative donors: a European Society for Blood and Marrow Transplantation registry retrospective analysis. Lancet Haematol 2019;6(11):e573-e584

48 Kindwall-Keller TL, Ballen KK. Alternative donor graft sources for adults with hematologic malignancies: a donor for all patients. Oncologist 2017;22(9):1125-1134

49 Stone RM, Mandrekar SJ, Sanford BL, et al. Midostaurin plus chemotherapy for acute myeloid leukemia with a FLT3 mutation. N Engl J Med 2017;377(5):454-464

50 Voso MT, Larson RA, Jones D, et al. Midostaurin in patients with acute myeloid leukemia and FLT3-TKD mutations: a subanalysis from the RATIFY trial. Blood Adv 2020;4(19):4945-4954

51 Wei AH, Tiong IS. Midostaurin, enasidenib, CPX-351, gemtuzumab ozogamicin, and venetoclax bring new hope to AML. Blood 2017;130(23):2469-2474

52 Burd A, Levine RL, Ruppert AS, et al. Precision medicine treatment in acute myeloid leukemia using prospective genomic profiling: feasibility and preliminary efficacy of the Beat AML Master Trial. Nat Med 2020;26(12):1852-1858

53 Lai C, Doucette K, Norsworthy K. Recent drug approvals for acute myeloid leukemia. J Hematol Oncol 2019;12(1):100

54 Röllig C, Serve H, Hüttmann A, et al; Study Alliance Leukaemia. Addition of sorafenib versus placebo to standard therapy in patients aged 60 years or younger with newly diagnosed acute myeloid leukaemia (SORAML): a multicentre, phase 2, randomised controlled trial. Lancet Oncol 2015;16(16):1691-1699

55 Duchmann M, Micol J-B, Duployez N, et al. Prognostic significance of concurrent gene mutations in intensively treated patients with IDH-mutated AML: an ALFA study. Blood 2021;137(20):2827-2837

56 Quintás-Cardama A, Ravandi F, Liu-Dumlao T, et al. Epigenetic therapy is associated with similar survival compared with intensive chemotherapy in older patients with newly diagnosed acute myeloid leukemia. Blood 2012;120(24):4840-4845

57 DiNardo CD, Jonas BA, Pullarkat V, et al. Azacitidine and venetoclax in previously untreated acute myeloid leukemia. $\mathrm{N}$ Engl J Med 2020;383:17-629

58 DiNardo CD, Pollyea DA, Jonas BA, et al. Updated safety and efficacy of venetoclax with decitabine or azacitidine in treatment-naïve, elderly patients with acute myeloid leukemia. Blood 2017;130:2628-2638 
59 DiNardo CD, Rausch CR, Benton C, et al. Clinical experience with the BCL2-inhibitor venetoclax in combination therapy for relapsed and refractory acute myeloid leukemia and related myeloid malignancies. Am J Hematol 2018;93(3):401-407

60 Fathi AT, DiNardo CD, Kline I, et al. AG221-C-001 Study Investigators. Differentiation syndrome associated with enasidenib, a selective inhibitor of mutant isocitrate dehydrogenase 2: analysis of a phase $1 / 2$ study.JAMA Oncol 2018;4(8):1106-1110

61 DiNardo CD, Stein EM, de Botton S, et al. Durable remissions with ivosidenib in IDH-1-mutated relapsed or refractory AML. N Engl J Med 2018;378(25):2386-2398

62 Daver N, Boddu P, Garcia-Manero G, et al. Hypomethylating agents in combination with immune checkpoint inhibitors in acute myeloid leukemia and myelodysplastic syndrome. Leukemia 2018;32(5):1094-1105

63 Craddock C, Labopin M, Robin M, et al. Clinical activity of azacitidine in patients who relapse after allogeneic stem cell transplantation for acute myeloid leukemia. Haematologica 2016;101(7):879-883

64 Ghosh K, Swaminathan S, Madkaikar M, Gupta M, Kerketta L, Vundinti B. FLT3 and NPM1 mutations in a cohort of AML patients and detection of a novel mutation in tyrosine kinase domain of FLT3 gene from Western India. Ann Hematol 2012;91(11):1703-1712

65 Büchner T, Berdel WE, Schoch C, et al. Double induction containing either two courses or one course of high-dose cytarabine plus mitoxantrone and postremission therapy by either autologous stem-cell transplantation or by prolonged maintenance for acute myeloid leukemia. J Clin Oncol 2006;24(16):2480-2489

66 Mao C, Fu XH, Yuan JQ, et al. Interleukin-2 as maintenance therapy for children and adults with acute myeloid leukaemia in first complete remission. Cochrane Database Syst Rev 2015;201511(11):CD010248

67 Oran B, de Lima M, Garcia-Manero G, et al. A phase 3 randomized study of 5-azacitidine maintenance vs observation after transplant in high-risk AML and MDS patients. Blood Adv 2020;4(21):5580-5588

68 Marcucci G, Geyer S, Laumann K, et al. Combination of dasatinib with chemotherapy in previously untreated core binding factor acute myeloid leukemia: CALGB 10801. Blood Adv 2020;4(4):696-705
69 Philip C, George B, Ganapule A, et al. Acute myeloid leukaemia: challenges and real world data from India. $\mathrm{Br}$ J Haematol 2015;170(1):110-117

70 Ganapule A, Nemani S, Korula A, et al. Allogeneic stem cell transplantation for acute myeloid leukemia: evolution of an effective strategy. J Glob Oncol 2017;3(6):773-781

71 George B, Menon H, Bhurani D, et al. A prospective observational multi-institutional study on fungal infections following chemotherapy for acute myeloid leukemia (MISFIC Study): a real world scenario from India. Indian J Hematol Blood Transfus 2020;36(1):97-103

72 Bahl A, Sharma A, Raina V, et al. Long-term outcomes for patients with acute myeloid leukemia: a single-center experience from AIIMS, India. Asia Pac J Clin Oncol 2015;11(3):242-252

73 Kalaiyarasi JP, Ganesan P, Kannan K, et al. Outcomes of intensive treatment of adult acute myeloid leukemia patients: a retrospective study from a single centre. Indian J Hematol Blood Transfus 2019;35(2):248-254

74 Saikia TK, Bakshi A, Bhagwat R, et al. Outcome of acute myeloid leukaemia in adults: a retrospective analysis. Natl Med J India 2005;18(1):12-15

75 Tandon N, Banavali S, Menon H, Gujral S, Kadam PA, Bakshi A. Is there a role for metronomic induction (and maintenance) therapy in elderly patients with acute myeloid leukemia? A literature review. Indian J Cancer 2013;50(2):154-158

76 Kapoor A, Beniwal SK, Kalwar A, et al. Metronomic therapy with oral 6-mercaptourine in elderly acute myeloid leukemia. South Asian J Cancer 2016;5:70-72

77 Thol F, Schlenk RF, Heuser M, Ganser A. How I treat refractory and early relapsed acute myeloid leukemia. Blood 2015;126(3):319-327

78 Burnett AK, Goldstone A, Hills RK, et al. Curability of patients with acute myeloid leukemia who did not undergo transplantation in first remission. J Clin Oncol 2013;31(10):1293-1301

79 Duval M, Klein JP, He W, et al. Hematopoietic stem-cell transplantation for acute leukemia in relapse or primary induction failure. J Clin Oncol 2010;28(23):3730-3738

80 Cummins KD, Gill S. Chimeric antigen receptor T-cell therapy for acute myeloid leukemia: how close to reality. ? Haematologica 2019;104(7):1302-1308

81 Halpern AB, Lyman GH, Walsh TJ, Kontoyiannis DP, Walter RB. Primary antifungal prophylaxis during curative-intent therapy for acute myeloid leukemia. Blood 2015;126(26):2790-2797 